Marušič, A. \& Farmer, A. (200I) Genetic risk factors as possible causes of the variation in European suicide rates. British Journal of Psychiatry, 179, 194-196.

D. Lester The Richard Stockton College of New Jersey, PO Box 195, Jim Leeds Road, Pomona, NJ 08240-0195, USA

S. V. Kondrichin Minsk Regional Hospital, Minsk, Belarus

Authors' reply: We are grateful to Lester \& Kondrichin for pointing out the high correlations between the suicide rates in 30 countries with the percentage of FinnoUgrians in the population, and of the negative correlations of suicide rates with the proportions of people with blood type $\mathrm{O}$ in different countries. This certainly provides additional evidence in support of our hypothesis.

Tunstall is more critical and his important comments require a considered response. He states that we have not addressed the issue of other sociocultural factors that may be relevant to the differences in European suicide rates. It has been pointed out elsewhere (e.g. Diekstra, 1993) that rate variation due to some such factors evens out when considered across countries, and can probably be ignored. Also, as we have pointed out, sociocultural explanations alone cannot explain the rate found in our 'black swan' example, Slovenia.

For brevity in a short editorial, we did not explore the 'potential confounder' of the prevalence of psychiatric disorder in different countries in our paper, although contrary to Tunstall's assertion, we have not neglected to discuss the complex relationship between alcohol consumption and suicide. Not only do we consider in some detail the possible malignant interaction between alcohol exposure and genetic constitution in Slovenia, but we also point out the complex association between alcohol consumption and suicide rates elsewhere in Europe, citing Sweden and France as examples.

Tunstall suggests that Finland is a more 'anxious culture' than Sweden. While this may be true, we none the less contend that such cultural anxiety would also have genetic underpinnings. Measures of trait constructs such as neuroticism have been shown to be, in part, genetically determined, and many of the risk factors previously believed to be entirely psychosocial have also been shown to be at least partly under genetic influence, including religious and political beliefs, marital difficulties and divorce (e.g. Kendler \& Karkowski-Shuman, 1997).

Tunstall challenges us to 'suggest genes that might plausibly affect suicidal behaviour ... which are shared by different FinnoUgrian-speaking populations but not by less suicide-prone populations'. In a recent genetic study of Slovenian suicides, we have replicated the tryptophan hydroxylase polymorphism previously reported in the Finnish population (further details available from the authors upon request). The same polymorphism has not been replicated in a UK study (Evans et al, 2000), a country less suicide-prone than either Slovenia or Finland.

Tunstall also suggests that the differences between Slovenia and its neighbours result from ' 40 years of separation', using the analogy of the USSR. Communism under Tito was far less restrictive and deprived, in terms of lifestyle and travel opportunities, than in the former Soviet Republics. In addition, why does the neighbouring country of Croatia, which experienced the same ' 40 years of separation', consistently report lower suicide rates (Pavlović \& Marušič , 2001) if this were the only explanation of the high Slovenian rates?

Finally, Tunstall suggests that a more realistic target for future research would be the detection of genetic influences on impulsivity. This is exactly what we are planning to do.

Diekstra, R. F. W. (1993) The epidemiology of suicide and parasuicide. Acta Psychiatrica Scandinavica Supplementum, 37I, 9-20.

Evans, J., Reeves, B., Platt, H., et al (2000) Impulsiveness, serotonin genes and repetition of deliberate self-harm (DSH). Psychological Medicine, 30 1327-1334.

Kendler, K. S. \& Karkowski-Shuman, L. (1997) Stressful life events and genetic liability to major depression: genetic control of exposure to the environment. Psychological Medicine, 27, 539-547.

Pavlović, E. \& Marušič, A. (200I) Suicide in Croati and in Croatian immigrant groups in Australia and Slovenia. Croatian Medical Journal, 42, 669-672.

A. Marušič, A. Farmer Social, Genetic \& Developmental Psychiatry Research Centre, Institute of Psychiatry, De Crespigny Park, Denmark Hill, London SE5 8AF, UK

\section{Aggression in schizophrenia: assessment and prevalence}

In a recent paper Jones et al (2001) reported an association of aggressive behaviour in schizophrenia with catechol-O-methyltransferase genotype. The authors studied a sample of 136 males and 44 females with schizophrenia. Aggression in patients was clinically assessed by means of the Overt Aggression Scale (OAS; Yudofski et al, 1986). The patients in this sample showed a surprisingly high level of aggression: $52 \%$ verbal aggression in male patients $(46 \%$ in females), $39 \%$ aggression against objects (25\% in females), $23 \%$ against self ( $9 \%$ females) and $39 \%$ against other people $(34 \%$ females) as measured by the OAS. Data on prevalence of aggression and violence in people with schizophrenia differ widely depending on definition and assessment period but most clinical studies in this field have shown lower rates, at least of physical aggression (for review see Schanda \& Taylor, 2001; see also Monahan et al, 2000).

In a recent retrospective study we evaluated the patient files of all patients with ICD-9 schizophrenia admitted to the psychiatric hospital of the University of Munich between 1990 and 1995 ( $n=2093$ ). Relevant socio-demographic, clinical and psychopathological data were evaluated. Fourteen per cent of patients $(n=292)$ met the criteria for aggression (verbal and physical) on admission (Soyka \& Ufer, 2002).

Jones et al feel that aggression may even be underestimated in their sample. Recent data suggest that the risk of violence is indeed overlooked in psychiatric patients. Sanders et al (2000) pointed out that while psychiatric patients are asked about suicidal ideas, aggression and the risk of violence are frequently neglected even in patients with clearly violent thoughts.

I have some concerns over whether a single rating scale can be valid and reliable enough to assess aggression adequately in schizophrenia, especially for genetic studies. Aggression and violence in schizophrenia are difficult to predict (Steadman et al 1998; Wallace et al 1998; Monahan et al, 2000 ) and can be both trait or state phenomena in schizophrenia. The OAS is a sensible instrument in this field but aggression is a multi-dimensional phenomenon. In most studies on that issue data from different sources are utilised (Swanson et al, 2000). Steadman et al (2000) have proposed an actuarial tool for assessing the risk of violence which has been evaluated in civil psychiatric patients (Monahan et al, 2000). Beside clinical interviews and specific psychopathological scales a broad number of other diagnostic instruments can be used to assess aggression and the risk for violence 
in psychiatric patients. A few of them may be mentioned: the Buss-Durkee Hostility Inventory with its sub-scales including 'physical aggression' (Buss \& Durkee, 1957) or the Brown-Goodwin assessment for lifetime history of aggression (Brown et al, 1979). Assessment and classification of such complex phenomena as aggression should not be based on only one scale, especially in genetic studies with their substantial clinical and possibly forensic/legal implications. Nevertheless, we hope that this research may provide more insight into the biological mechanisms underlying aggression.

Brown, G. L., Goodwin, F. K., Ballenger, J. C., et al (1979) Aggression in humans: correlates with cerebrospinal fluid amine metabolites. Psychiatry Research, I, |3|-139.

Buss, A. H. \& Durkee, A. (1957) An inventory for assessing different kinds of hostility. Journal of Consulting Psychology, 2I, 343-349.

Jones, G., Zammit, S., Norton, N., et al (200I) Aggressive behaviour in patients with schizophrenia is associated with catechol-O-methyltransferase genotype. British Journal of Psychiatry, 179, 35I-355.

Monahan, J., Steadman, H. J., Appelbaum, P. S., et al (2000) Developing a clinically useful actuarial tool for assessing violence risk. British Journal of Psychiatry, I76, 312-319.

Sanders, J., Milne, S., Browne, P., et al (2000) Assessment of aggression in psychiatry admissions: semistructured interview and case note survey. BMJ, 320,1112

Schanda, H. \& Taylor, P. (200I) In-patient violence: frequency, risk factors, preventive strategies (in German). Fortschritte Neurologie Psychiatrie, 69, 443-452.

Soyka, M. \& Ufer, S. (2002) Aggression in schizophrenia: prevalence, psychopathological and sociodemographic correlates (in German). Fortschritte Neurologie Psychiatrie, in press.

Steadman, H. J., Mulvey, E. P., Monahan, J., et al (1998) Violence by people discharged from acute psychiatric inpatient facilities and by others in the same neighborhoods. Archives of General Psychiatry, 55, I-9.

_ , Silver, E., Monahan, J., et al (2000) A

classification tree approach to the development of actuarial violent risk assessment tools. Law and Human Behavior, 24, 83-100.

Swanson, J.W., Swartz, M. S., Borum, R., et al (2000) Involuntary out-patient commitment and reduction of violent behaviour in persons with severe mental illness. British Journal of Psychiatry, 176, 324-331.

Yudofski, S. C., Silver, J. M., Jackson, W., et al (1986) The Overt Aggression Scale for the objective rating of verbal and physical aggression. American Journal of Psychiatry, 143, 35-39.

Wallace, C., Mullen, P., Burgess, P., et al (1998) Serious criminal offending and mental disorder. Care linkage study. British Journal of Psychiatry, I72, 477-484.

M. Soyka Psychiatric Hospital, University of Munich, Nußbaumstr. 7, 80336 München, Germany; e-mail: Michael.Soyka@psy.med.uni-muenchen.de

\section{Post-traumatic stress disorder and management of stillbirth}

Lovett (2001), commenting on our article 'Incidence, correlates and predictors of post-traumatic stress disorder in the pregnancy after stillbirth' (Turton et al, 2001) took issue with our reporting a possible association between post-traumatic stress disorder and holding the dead infant which did not reach statistical significance.

We should like to make two points. First, we were at pains to make it clear that numbers were small and not significant statistically. Second, although your correspondent could not know this at the time of writing, we have subsequently published a paper reporting a significant relationship between seeing the dead infant and disorganisation of mother-infant attachment in the next-born child at the age of 12 months (Hughes et al, 2001). This was an unexpected finding for us.

Our main concern is that a profound change in clinical practice (seeing and holding the dead infant) was introduced with great enthusiasm in maternity units in the UK and elsewhere on the basis of limited and non-systematic clinical observation. Our published findings to date do not offer any evidence in support of this practice. We concur with Dr Lovett that this is an area which demands further investigation and rigorous evaluation.

Hughes, P., Turton, P., Hopper, E., et al (200I) Disorganised attachment behaviour among infants born subsequent to stillbirth. Journal of Child Psychology and Psychiatry, 42, 791-801.

Lovett, K. F. (200I) PTSD and stillbirth (letter). British Journal of Psychiatry, 179, 367.

Turton, P., Hughes, P., Evans, C. D. H., et al (200I) Incidence, correlates and predictors of post-traumatic stress disorder in the pregnancy after stillbirth. British Journal of Psychiatry, I78, 556-560.

P. Turton, P. Hughes Parent Child Research Group, Department of Psychiatry, Jenner Wing, St George's Hospital Medical School, London SWI7 ORE, UK

\section{Psychiatric morbidity and elderly offenders}

While I agree entirely with Fazel et al (2001) that there is an unmet need for psychiatric care for elderly offenders, I wonder whether this need is even greater than is implied by their paper. It is important not to forget those elderly people who do not actually end up in prison but have committed crimes. Yorston (1999) notes that the elderly are less likely than younger offenders to have custodial sentences or fines imposed and are more likely to receive probation orders. Lynch (1988) postulated that the public's sympathy for the perceived frailty of the elderly is likely to lead to this group being treated more leniently. Bergman \& Amir (1973) have also noted a tendency for families to hide deviance, which may lead to offending behaviour in this group being underreported.

One revelation to me which emerges from Fazel et al's paper was the relatively high number of offenders imprisoned for drug offences (29/203). Older studies (e.g. Taylor \& Parrott, 1988) suggested that drug-related crime was of a much lower incidence: indeed, in their study of elderly custodial remand prisoners none aged 55 and over had been charged with a drugrelated offence, although they noted that misuse of alcohol appeared to rise steadily with age. I wonder whether Fazel et al are showing us that the victims of the drugs culture, traditionally thought to have been established in the UK in the 1960s, are now starting to feature among the elderly?

Bergman, S. \& Amir, M. (1973) Crime and delinquency among aged in Israel. Israel Annals of Psychiatry and Related Disciplines, II, 33-48.

Fazel, S., Hope, T., O’Donnell, l., et al (200I) Hidden psychiatric morbidity in elderly prisoners. British Journal of Psychiatry, 179, 535-539.

Lynch, S. (1988) Criminality in the elderly and psychiatric disorder. A review of the literature. Medicine, Science and the Law, 28, 65-78.

Taylor, P. J. \& Parrott, J. M. (1988) Elderly offenders. A study of age-related factors among custodially remanded prisoners. British Journal of Psychiatry, 152 , 340-346.

Yorston, G. (1999) Aged and dangerous. Old age forensic psychiatry. British Journal of Psychiatry, 174, 193-195.

A.Thompsell Maudsley Hospital, Denmark Hill, London SE5 8AZ, UK

Elderly mentally disordered offenders are underresearched and poorly understood, but Fazel et al (2001a) demonstrated high levels of 'hidden' psychiatric morbidity in a sample of male prisoners over 60 years of age.

The cases of the former Chilean dictator Augusto Pinochet and of Ernest Saunders, involved in the Guinness financial affair, illustrated the inherent difficulties of the older person in the forensic setting. 